\title{
Zeus na religião grega: antropomorfismo, hegemonia e atividade celeste nos testemunhos de Homero e de Hesíodo
}

\author{
Antônio Orlando Dourado Lopes \\ FALE-UFMG \\ douradolopes@hotmail.com
}

\begin{abstract}
Greek religion is marked both by Zeus' hegemony and the plurality of its pantheon. These two aspects tend to be complementary, but may conflict under the influence of the incidents produced by their divergent interests and their mutual relationship. In this study I propose to define Greek religious anthropomorphism by specifying some general similarities and differences to other ancient religions, particularly as regards the supreme gods. I examine the main passages in the homeric and the hesiodic poems where Zeus' characteristics contribute decisively to Greek religious anthropomorphism: his intelligence (as opposed to his strength), his celestial origin and his role as king of the gods.
\end{abstract}

KEYWORDS: Greek religion; homeric poems; hesiodic poems.

Saepe malum hoc nobis, si mens non laeua fuisset,

de caelo tactas memini praedicere quercus.

Há muito, um infortúnio assim, se bem lembro, carvalhos, pelo céu fulminados, previram.

(Virgílio, Bucólicas I, 16-17) ${ }^{1}$

A superioridade de Zeus aproxima a religião grega de outras religiões politeístas, às quais a existência de um deus supremo parece conferir alguma estabilidade, estruturando o panteão divino. Como o deus supremo tem tendência a não intervir diretamente na vida dos homens, sua autoridade permanece estranha aos conflitos suscitados tanto por ele quanto pelas demais divindades. Na prática, a superioridade de sua força desempenha uma função, sobretudo, potencial. Esse aspecto aparece na ameaça que ele faz aos que transgredirem a proibição de intervir na guerra (Ilíada VIII, 5-27). Sua distância a respeito dos outros deuses é afirmada de modo peremptório pelo título que ele se atribui a si mesmo duas vezes no poema: Zeùs hypatos méstor, "Zeus o líder excelso" (Ilíada VIII, 22 e XVII, 339, sempre no acusativo). ${ }^{2}$ Ele seria capaz de

\footnotetext{
${ }^{1}$ Cf. Virgílio. Bucólicas. Tradução e comentário de Raimundo Carvalho. Belo Horizonte: Tessitura/ Crisálida, 2005, p. 12-13.

2 Derivado de hypó, "sob", "abaixo de", hypatos pode significar "mais alto", "mais distante", ou, em sentido temporal, "último", "derradeiro" (cf. lat. summus, de sub). É difícil precisar o sentido do termo nas duas únicas ocorrências da expressão Zeùs hypatos méstor na Ilíada, a primeira numa fala do próprio Zeus, a segunda, numa de Heitor. Contudo, de um ponto de vista mais genérico, pode-se supor que o termo alude principalmente à superioridade do deus sobre os demais, além de marcar sua posição como o
} 
erguer por uma corda de ouro todos que tentassem medir forças com ele (Ilíada VIII, $18-27){ }^{3}$

A realeza de Zeus entre os deuses não parece vincular-se diretamente, em Homero, à trifuncionalidade indo-europeia. Por outro lado, segundo Dumézil, a perspectiva indo-europeia das três funções estaria presente na Ilíada através da apresentação de Hera como deusa soberana, de Atena como deusa guerreira e de Afrodite como deusa relacionada com a fertilidade/ produtividade. ${ }^{4}$ Entre os mortais, o contexto de um acampamento de guerra teria impossibilitado que os heróis aqueus aparecessem segundo uma ótica tripartite, relegando a tripartição indo-europeia apenas ao lado dos troianos: Príamo seria o rei, Heitor o guerreiro e Páris, como o protegido de Afrodite, o representante da fertilidade/ produtividade. $^{5}$

No que diz respeito a Hesíodo, não há dúvida de que sua religião tem uma forte influência da representação homérica, para a qual os deuses são essencialmente humanos. ${ }^{6}$ Nós só podemos falar de "força" a seu respeito quando se trata de suas ações. Não há, portanto, "força", em sentido estrito, mas "deuses fortes", o que significa dizer que não há força divina que não se vincule a uma vontade. ${ }^{7}$ Zeus, por outro lado, age tanto por sua astúcia quanto por sua força, ambas a serviço de uma vontade insondável. Sua supremacia e soberania são decisivas no equilíbrio do politeísmo grego, sem que, todavia, sua força seja o único fator decisivo. ${ }^{8}$ Diversas histórias em torno às artimanhas

último de uma sequência, ou seja, aquele em que a sucessão atingiu a perfeição, revelando-lhe o verdadeiro sentido mas, também, pondo-lhe um término.

${ }^{3}$ Cf. Kullmann, W. Das Wirken der Götter in der "Ilias". Untersuchungen zur Entstehung der Frage des homerischen "Götterapparatts". Berlin: Akademie, 1956, p. 89 (nota 2).

${ }^{4}$ Cf. Dumézil, G. Homerus vindicatus (le troisième chant de 1' "Iliade"). In: L'oubli de l'homme et l'honneur des dieux et autres essais. Vingt-cinq esquisses de mythologie. 51-75. Paris: Gallimard, 1985, p. 15-30; em particular p. 16 (grifos do autor): "Hera manifesta constantemente seu nível de soberana, irmã e esposa de Zeus, e Atena lhe está constantemente subordinada, como o quer a articulação da segunda função à primeira: Hera lhe dá missões, ordens, geralmente guerreiras, que ela executa sem discussão".

${ }^{5}$ Cf. Dumézil, op. cit., p. 18-19.

${ }^{6}$ Cf. Snodgrass, A. Homero e os artistas. Texto e pintura na arte grega antiga. Tradução de L. A. M. Cabral e O. T. Serra. São Paulo: Odysseus, 2004 (em particular o capítulo 1: "O prestígio de Homero", p. 20-33).

${ }^{7}$ Desenvolvi esse tema em um breve estudo em vias de publicação: A força e o antropomorfismo dos deuses gregos. Considerações sobre a religião dos poemas homéricos. Aletria. Belo Horizonte, vol. XIX, 2009.

${ }^{8}$ Os dois poemas homéricos salientam a onisciência de Zeus, assim como o faz Hesíodo ao concluir suas versões do mito de Prometeu (Teogonia 613-616, e Trabalhos e dias 105). Ilíada XVI, 688-690: "Mas a

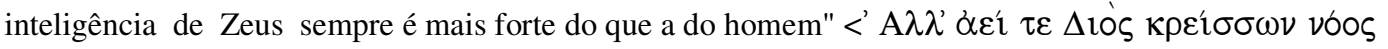
$\eta \bar{\eta} \pi \varepsilon \rho \alpha \nu \delta \rho o ́ \varsigma>$. É ele que põe mesmo o valente em fuga e lhe arranca a vitória efetivamente, ainda quando o incita a lutar". Odisseia V, 137-138 (Calipso consente a contra-gosto a partida de Ulisses): "Todavia, já que não é possível a um outro deus nem escapar à inteligência de Zeus porta-égide nem

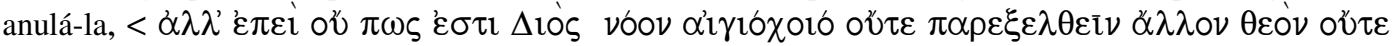


de que Zeus é vítima mostram a importância da astúcia no exercício de seu poder. Nessas ocasiões, ele também pode ver-se obrigado a abrir-se às negociações com os outros deuses. ${ }^{9}$ É, por sua vez, significativo, que o respeito devido à sua idade seja evocado algumas vezes na Ilíada, talvez como explicação para sua superioridade física, quando seu irmão quer disputar-lhe o poder. ${ }^{10}$

Uma outra característica que os poemas hesiódicos partilham com os homéricos é a importância dos deuses oriundos da adoração do céu e dos astros. É particularmente esse o caso de Zeus, originalmente um deus celeste. ${ }^{11}$ Observado no século XIX, esse $\alpha \lambda \imath \omega \sigma \alpha l>(\ldots) "$.
${ }^{9}$ Para a importância da inteligência como característica de Zeus, veja-se a prece que lhe dirige Menelau,
depois de matar o troiano Pisandro: "Zeus pai! dizem que superas a todos os demais em teu espírito, tanto
a homens quanto a deuses, e todas estas coisas decorrem de ti!" <

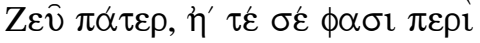

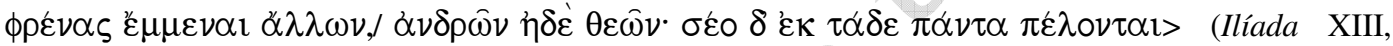
631-632). A negociação mais evidente de Zeus na Ilíada é sem dúvida com Hera no canto IV, 1-84.

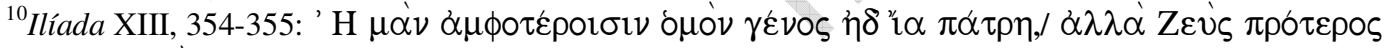

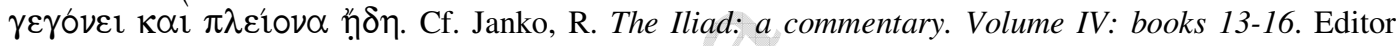
geral G. Kirk. Cambridge: University Press, 1992, ad loc., lembra que a variação

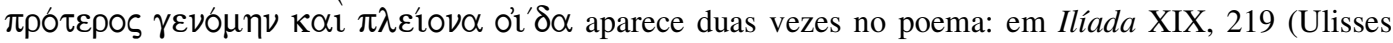
em relação a Aquiles) e XXI, 440 (Poseidon em relação a Apolo). Depois de comparar Ilíada V, 165-167 com as palavras de Agamêmnon em I, 186ss. e IX, 160ss., o mesmo autor conclui: "Em contraste com a disparidade trágica entre seu [scil. de Agamêmnon] estatuto e sua mediocridade enquanto chefe, a hierarquia divina combina nível e proeza numa só pessoa".

${ }^{11}$ Cf. Pfister, F. Epiphanie. In: von Pauly, A. F.; Wissowa, G.; Kroll, W.; Witte, K., Mittelhaus, K.; Ziegler, K. Realencyclopädie der Altertumswissenschaft. Suttgart/ München: 1894-1980. Suplemento 4. 1903, p. 277-323; em particular p. 315-316, e Chantraine, P. Le divin et les dieux chez Homère. In: Réverdin, O. (org.). La notion du divin depuis Homère jusqu'à Platon. Entretiens sur l'Antiquité Classique, 1. Vandoeuvres (Genebra): Fondation Hardt pour les Études Classiques, 1952, p. 47-94/ p. 55: "O deus grego (qualquer que seja em cada caso a origem das divindades) é, em larga medida, um deus indo-europeu. Não há nada a obter da palavra $\theta \varepsilon o ́ s$, cuja etimologia é ignorada, mas as outras línguas indo-europeias empregam um termo, que é em latim a palavra deus, que exprime a ideia de que o deus é

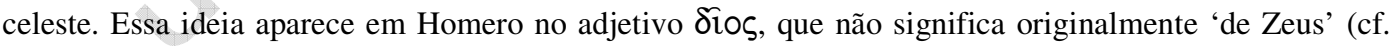
todavia Ilíada IX, 538), mas se aplica aos deuses enquanto são celestes e luminosos, como o indica a fórmula $\delta i \imath \alpha \theta \varepsilon \alpha ́ \alpha \nu$ (Ilíada XVIII, 388 etc.). Os deuses são igualmente designados pela expressão

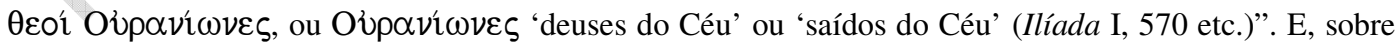
o nome de Zeus (p. 56): "Temos aqui um nome divino comum a muitas línguas porque a adoração do céu luminoso se acha sobre todo o domínio indo-europeu”. Huxley, G. L. Greek epic poetry. London: Faber \& Faber, 1969, p. 20-21, observa que a separação entre o céu e a terra nas cosmogonias mais antigas (de que Homero e Hesíodo só guardam vestígios) era o "primeiro acontecimento" e constitui a marca do mundo dos deuses. Para uma abordagem mais ampla dos deuses celestes em religiões diferentes, veja-se também Eliade, M. Traité d'histoire des religions. Paris: Payot, 1986, ${ }^{2} 402$ p., capítulo II: "Le ciel: dieux ouraniens, rites et symboles célestes”, p. 46-114, e Burkert, W. Mito e mitologia. Perspectivas do homem. Tradução de M. H. R. Pereira. Lisboa: Edições 70, 1992, p. 24: “O mito hitita da 'realeza no céu', com a sequência Anu- (Céu)-Kumarbi-Deus-do-tempo-atmosférico corresponde até ao pormenor à sucessão dos deuses em Hesíodo: uranos (Céu)-Cronos-Zeus. Aqui como lá o soberano interino não-bom castra e engole o deus do Céu, fato que mais tarde ainda o derrubará. Contudo, em posição e função, é-lhe comparável também o mole assassino Egisto, entre Agamêmnon e Orestes, o vingador de seu pai”. 
aspecto aparece até hoje como um dos principais pontos de vista para uma aproximação da religião grega como um todo. ${ }^{12}$

Os deuses gregos descendem da união da Terra com o Céu, seu filho, e são chamados nos poemas homéricos de "deuses celestes". ${ }^{13}$ A importância dada à sua ascendência celeste continua importante na tomada do poder pelos Cronidas, mediante a qual uma tripartição do mundo entre os três irmãos concede a Zeus o domínio celeste. Dessa forma, os deuses são "os celestes" nos dois sentidos de descenderem do Céu e de existirem graças a e sob o poder do deus do céu. Essa é, por assim dizer, a verdade olímpica da religião grega.

Tal como a conhecemos nos poemas homéricos, a relação de Zeus com os fenômenos atmosféricos nasce de uma evolução que não é rara nas religiões da antiguidade, e que consiste na passagem do domínio do céu àquele mais restrito da tempestade e da instabilidade climática. Segundo M. Eliade,

a "especialização" das divindades celestes em divindades do furacão e da chuva, assim como a acentuação de suas potências fecundantes, explica-se em grande parte pela estrutura passiva das divindades celestes e sua tendência a dar lugar a outras hierofanias, mais "concretas", mais nitidamente "personificadas", mais diretamente implicadas na vida cotidiana dos homens. Está aí um destino que deriva em primeiro lugar da transcendência do céu e da progressiva "sede de concreto" do homem. ${ }^{14}$

M. Eliade distingue duas linhas principais de desenvolvimento desses "deuses do furacão", salientando que "os dois tipos se entrecruzam sem cessa" na realidade das religiões:

$1^{\circ}$ o Deus do céu, senhor do mundo, soberano absoluto (déspota), guardião das leis; $2^{\circ}$ o Deus do céu, criador, o macho por excelência, esposo da Grande Deusa telúrica, distribuidor da chuva. ${ }^{15}$

\footnotetext{
12 Cf. Olender, M. Les langues du paradis. Aryens et Sémites: un couple providentiel. Paris: Gallimard/ Le Seuil, 2002, ${ }^{2}$ p. 216. A identificação dos sinais de intempérie como base das crenças religiosas indoeuropeias foi proposta pela primeira vez por A. Kuhn. Em 1863, F. M. Müller apresentou a interpretação meteorológica como uma das principais tendências da mitologia comparada do seu tempo (Nouvelles leçons sur la science du langage, 1863). A outra tendência indicada na primeira obra era a interpretação solar de certos mitos.

${ }^{13}$ Eroi oủpovíwves: Ilíada I, 570; XVII, 195 e XXIV, 612; Odisseia VII, 242; IX, 15 e XIII, 41; ou

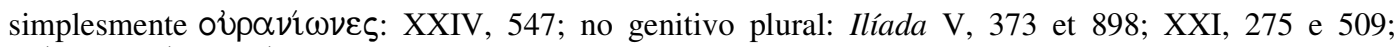

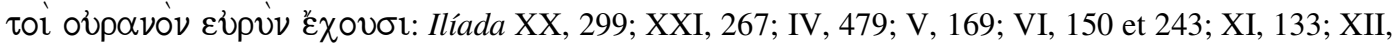
344; XIII, 55; XVI, 200; XXIII, 280; com oil no lugar de $\tau$ oí: Odisseia I, 67; IV, 378; XXII, 39.

${ }^{14}$ Cf. Eliade, op. cit., p. $80, \S 26$.

${ }^{15}$ Cf. Eliade, op. cit., p. 80: "Mas o que podemos afirmar sem hesitação é que o processo de especialização tende a delimitar com bastante precisão as jurisdições desses dois tipos divinos. Como
} 
O trovão tornou-se assim, muito naturalmente, a manifestação por excelência da presença longínqua mas poderosa de Zeus, da sua vontade e, de acordo com a ocasião, de sua fúria. ${ }^{16}$ Esse aspecto transparece nos diversos epítetos do deus que remetem aos fenômenos celestes: "que ama ou que lança o raio", "reunidor de nuvens", "que estremece ou que ressoa no alto do céu", "reunidor de relâmpagos", "que lança relâmpagos". ${ }^{17}$ Lembremo-nos ainda de que frequentemente, em Homero, a chuva é "de Zeus". 18

exemplo típico da primeira classe - dos soberanos e dos guardiões das leis - citemos T’ien, Varuna, Ahura Mazda. A segunda classe - a dos 'fecundadores' - é morfologicamente mais rica. Mas notemos, em todas as figuras que se agrupam nessa rubrica, as seguintes constantes: a hierogamia com a deusa Terra; o trovão, a tempestade e a chuva; as relações rituais e míticas com o touro. Entre os deuses dessa segunda classe - 'fecundadores' mas também 'deuses da tempestade' - pode-se citar Zeus, Min e o deus hitita, mas também Parjanya, Indra, Rudra, Hadad, Ba'al, Jupiter Dolichenus, Thôrr; numa palavra, o que se chama de 'os deuses da tempestade'."

${ }^{16}$ Cf. Eliade, op. cit., p. 76-77: "O relâmpago era a arma de Zeus e os lugares atingidos pelo raio, $\varepsilon v \eta \lambda \hat{v} \sigma \iota \alpha$, eram-lhe consagrados. Os títulos de Zeus são transparentes e testemunham todos, mais ou menos diretamente, de suas relações com a tempestade, a chuva, a fertilidade. (...) Esse elemento criador está evidentemente em Zeus não no plano cosmogônico (já que não foi ele que fez o universo), mas no plano bio-cósmico: ele comanda as fontes da fertilidade, ele é o mestre da chuva.Ele é 'criador' já que ele é 'fecundador' (às vezes ele é também um touro; cf. o mito de Europa). Ora, essa 'criação' de Zeus depende primeiramente de todo o drama meteorológico, em primeiro lugar da chuva. Sua supremacia é ao mesmo tempo de ordem paternal e soberana: ele garante o bom estado da família e da Natureza por suas forças criativas, de uma parte, e por sua autoridade de guardião das normas, de outra". Fränkel, H. Dicthung und Philosophie des frühen Griechentums. Eine Geschichte der griechische Epik, Lyrik und Prosa bis zur Mitte der fünften Jahrhunderts, p. 80 (nota 10): "Relâmpago e trovão são a única língua nas quais o Senhor fala aos mortais". Veja-se ainda Reinhardt, K. "Die Abenteuer der Odyssee", "Personnification und Allegorie". In: Vermächtnis der Antike. Essays zur Philosophie und Geschichtschreibung. Göttingen: Vandenhoeck \& Ruprecht, 1989, p. 7-40; em particular p. 114 (sobre o trovão enviado por Zeus no episódio do encontro de Ulisses com Éolo): "Tão necessária quanto a advertência, a punição também faz parte dessa situação. E notadamente a que se cumpre através de Zeus. Mas ela só pode ser uma tempestade e um trovão (...). Apesar do empréstimo de Ilíada XII, 385 e XVI, 742 , a tempestade também é poetizada de uma maneira bela. Mas somente como poesia tem ela peso suficiente para compensar poética e moralmente como consequência o que a precedeu".

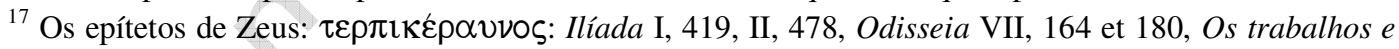

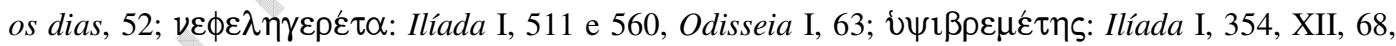

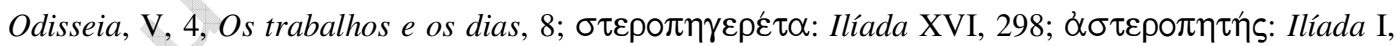
580, Teogonia, 390. Veja-se em particular Séchan, L. apêndice: “Mythologie et religion”. In: Bailly, A. Dictionnaire Grec-Français. Rédigé avec le concours de E. Egger. Paris: 1894; édition revue par L. Séchan et P. Chantraine avec, en appendice, de nouvelles notices de mythologie et religion par L. Séchan, Paris, Hachette, $1963^{2,6}$ p. 2224-2226, s. v. "Zeus": "Seu nome, que fiugura sobre as tabuletas micênicas,

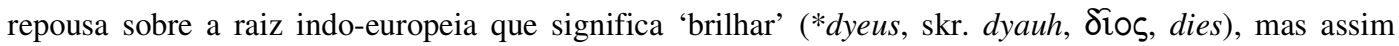

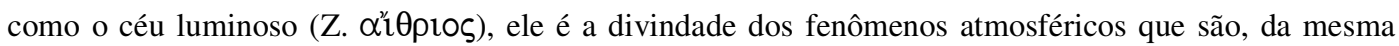
forma, os presságios: trovão, raio, chuva torrencial, acumulação de nuvens (...). Os meteoritos e os machados de pedra, seus sucedâneos, são-lhe primitivamente consagrados, e os ladrilhos/ quadrados de relâmpago, como a águia porta-relâmpago, permanecerão os atributos clássicos do deus às vezes

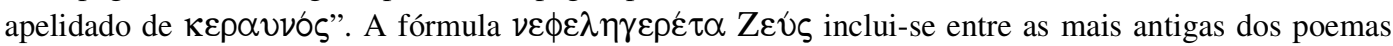
homéricos (West, M. The rise of the greek Epic. Journal of Hellenic Studies. Vol. CVIII, 1988, p. 151172, em particular p. 169-170). A referência aos fenômenos naturais também aparece nos epítetos do deus posteriores aos poemas homéricos e aos de Hesíodo (segundo Vernant, J.-P. Structures du mythe. In: Les origines de la pensée grecque. Paris: Quadrige/ Presses Universitaires de France, 1990,

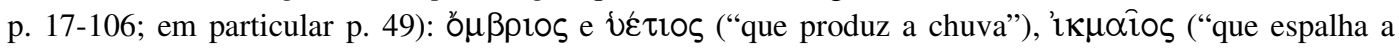


A extraordinária agilidade dos deuses também pode evocar os corpos celestes: o deslocamento de Atena é comparado ao movimento de um astro; a imagem de Ares, que desaparece diante de Diomedes, é comparada com o vapor de um vento de tempestade (Ilíada IV, 75-80 e V, 864-867); ${ }^{19}$ a neve é evocada para exprimir o brilho esbranquiçado do movimento de Íris; por causa de sua velocidade, a deusa é "a que tem os pés de tempestade". ${ }^{20}$

Apesar de todas essas associações entre os deuses e os fenômenos atmosféricos, é preciso notar que essa relação permanece rigorosamente externa. A esse respeito, Homero e Hesíodo contrastam fortemente com outras tradições poéticas antigas, bem como com a própria mitologia grega. ${ }^{21}$ Mesmo se ele guarda seus atributos meteorológicos, Zeus permanece nos poemas homéricos e nos de Hesíodo

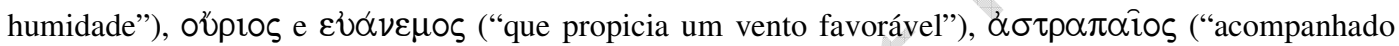

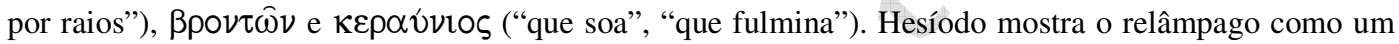
presente dos ciclopes a Zeus (Teogonia, 139-141; em 687-712 eles aparecem como as armas do deus no que West, M. Hesiod. Theogony, ad 687ss., chama de "a aristeía de Zeus"). Lembremo-nos, finalmente, de que também Poseidon se manifesta pelos fenômenos atmosféricos, sendo capaz de sacudir a terra e de

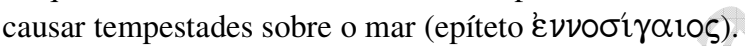

${ }^{18} \Delta$ ios ö $\mu$ ßpos (Ilíada V, 91 e XII, 286; Odisseia IX, 111 et 358; $\Delta$ iós ö $\mu \beta p \omega$ : Ilíada XI, 493. Vejamse também as expressões que remetem ao caráter infinito e, nesse sentido, divino, da chuva:

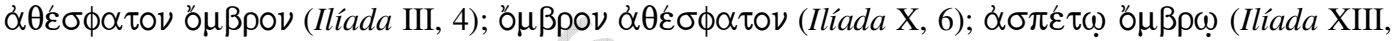
139).

${ }_{19}$ O esplendor é frequentemente uma característica do corpo divino, o que torna muito natural a comparação com os fenômenos celestes. Veja-se meu comentário a esse respeito em Dourado-Lopes, A. O. O. L'effectivité improbable. Une étude de l'adverbe $\rho \varepsilon i \hat{\alpha} \alpha$, de l'adjectif $\chi \alpha \lambda \varepsilon \pi \delta$ st des termes qui en dérivent dans les poèmes homériques. Tese de doutorado defendida junto à Université de Strasbourg sob a orientação de J. Frère. Strasbourg: 2009, 523 p., em particular "3.2.1 L'épiphanie et la luminosité dans les poèmes homériques", p. 415-434 (disponível on-line em http://eprints-u.umb-strasbg.fr/view/name/). ${ }^{20}$ A comparação do movimento de Íris com a neve aparece em Ilíada XV, 170-173. O epíteto da deusa é

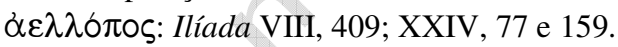

${ }^{21}$ Cf. Kullmann, W. Das Wirken der Götter in der "Ilias". Untersuchungen zur Entstehung der Frage des homerischen "Götterapparatts", p. 89-90, que observa: "Na crença do povo colocavam-se facilmente em relação certas manifestações meteorológicas extraordinárias e a aproximação de um deus. (...) O que é decisivamente homérico é que a epifania divina não assimilada ao fenômeno meteorológico, mas somente comparada com ele". Detienne, M. L'invention de la mythologie. Paris: Gallimard, 1981, p. 3132, lembra-nos dos teóricos do século XIX que atribuíram a origem da mitologia à experiência dos gregos concernente à natureza: uns, como $\mathrm{F}$. Max-Müller, trouxeram os mitos para o espetáculo do sol $\mathrm{e}$ da luz; outros, como A. Kuhn, explicaram-nos como uma tradução das convulsões da natureza. Esse tipo de teoria não é mais aceito, mas mesmo assim testemunha da importância evidente concedida pelos mitos aos fenômenos naturais. Para o que diz respeito aos poemas homéricos, observemos com Richardson, N. The "Iliad": a commentary. Vol. VI: books XXI-XXIV. Cambridge: University Press, 1993, p. 16, que eles valorizam muito pouco as descrições da ação regular do clima, e que os acontecimentos excepcionais supõem sempre a atividade divina. Veja-se também Griffin, J. The epic cycle and the uniqueness of Homer. Journal of Hellenic Studies. Vol. XCVII, p. 39-53, 1977, em particular p. 47, que observa que nos poemas homéricos Zeus não fulmina os homens com seu trovão, como fez com Capaneu, na epopeia tebana, e com Idas, nos Cantos Cipriotas, "mas, ao contrário, envia-o somente como um sinal e uma advertência", o que, aliás, só acontece no canto VIII" (o autor remete a M. Nilsson. Opuscula selecta, I, p. $359)$. 
fundamentalmente o Senhor dos deuses. ${ }^{22}$ A mesma associação também é feita no sentido inverso, quando o poeta exprime as manifestações mais extremas do ardor guerreiro, individuais e coletivas, evocando a impetuosidade animal ou as convulsões da natureza.

Às vezes Zeus intervém na guerra, mais frequentemente por meio de seus atributos meteorológicos. Esse poder aparece indiretamente quando uma tempestade é atribuída à sua cólera num símile que ressalta o impacto causado pela impetuosidade e o número das éguas troianas:

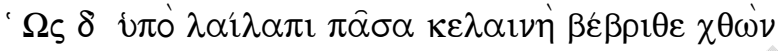

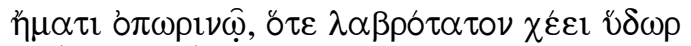

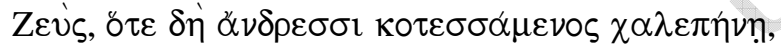

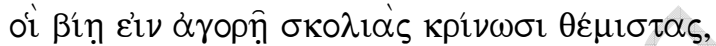

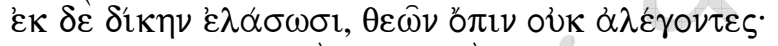

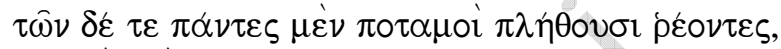

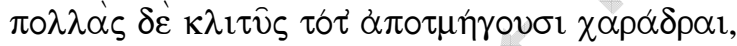

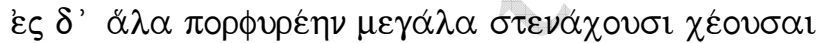

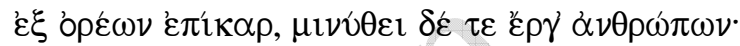

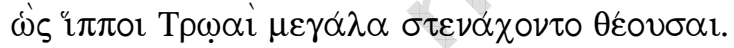

Assim como toda a terra esmagada sob uma negra tempestade num dia invernal, quando Zeus despeja furiosa água, encolerizado, afligindo os homens que na praça decidem brutalmente por sentenças tortuosas e expulsam a justiça, negligentes do respeito aos deuses; todos os rios correm cheios, as torrentes sulcam as colinas, urrando, montanha abaixo, ao correrem para o mar sombrio, aniquilando as obras humanas; alto assim urravam em correria as éguas troianas. ${ }^{23}$

Os efeitos devastadores da tempestade são aqui interpretados como consequência da intenção cruel do deus. A crença nas divindades antropomórficas faz suspeitar-se da presença de um deus atrás dos acontecimentos mais fantásticos e mais terríveis. Para exprimir a potência indomável das éguas, o poeta nos remete ao momento em que céu e terra se fundem, os rios deixam seus leitos porque guiados por uma vontade de destruição. ${ }^{24}$

${ }^{22}$ Cf. Fränkel, H. Dichtung und Philosophie des frühen Griechentums. Eine Geschichte der griechischen Epik, Lyrik und Prosa bis zur Mitte des fünften Jahrhunderts, p.64-65: "Zeus é sem dúvida, segundo seus epítetos, o deus da tempestade, mas ele age quase o tempo todo como o mais alto senhor de todo o mundo. Ele não precisa fazer nenhuma tempestade...".

${ }^{23}$ Cf. Ilíada XVI, 384-393.

${ }^{24} \mathrm{O}$ paralelismo entre o acontecimento da cólera e a instabilidade meteorológica também aparece no emprego do verbo '̇́ínuı, "deixar ir": às vezes ele indica a cólera dos homens (Ilíada I, 22-25 = 376379; XIII, 444 = XVI, 613 = XVII, 529) e, em Odisseia XXIV, 539, o gesto de Zeus de lançar o raio. Os rios crueis do canto XVI antecipam de algum modo a luta de Aquiles contra os rios do canto XX. A 
A relação estabelecida nessa passagem entre a cólera de Zeus e a catástrofe causada por sua tempestade já há muito intriga os críticos. A comparação das éguas troianas com a tempestade de Zeus é, com efeito, uma das poucas passagens do poema em que a relação entre o deus soberano e a justiça dos homens é afirmada de modo inequívoco. Retomando os argumentos desse debate, Kip ressaltou dois aspectos principais:

a-Nos poemas homéricos a cólera dos deuses não é arbitrária, mesmo se eles não se ocupam diretamente da justiça dos homens;

b-Já que Ilíada XVI, 384-393 é um símile, não é preciso identificar o "Zeus" a que se refere aqui o poeta com o da história do poema nem, por outro lado, "os homens que na praça decidem brutalmente por sentenças tortuosas e expulsam a justiça, negligentes da veneração dos deuses" (387-388) com os troianos. Aqui a intenção do poeta concentra-se na impetuosidade das éguas troianas e não na razão da cólera de Zeus.

O poeta não teria nenhuma razão para restringir a afirmação da preocupação de Zeus com a justiça apenas a essa passagem. ${ }^{25}$ É a tensão do primeiro dos aspectos acima com o segundo que torna difícil sua interpretação. Alguns críticos, como Lloyd-Jones e Janko, argumentam em favor da afirmação do compromisso de Zeus com a justiça, enquanto outros, como Yamagata, salientam o sentido contraditório e vago da passagem. ${ }^{26}$ De minha parte, eu aceito o ponto de vista de Kip, que me permite enfatizar o caráter surpreendente e impetuoso do comportamento divino, em particular o de Zeus. Zeus, quando quer, pode ocupar-se da justiça entre os homens.

A comparação entre a violência dos guerreiros e os cataclismas naturais também é feita em outras passagens. No canto IV, por exemplo, o poeta compara o deslocamento impetuoso dos aqueus com o mar silencioso em movimento que fustiga violentamente a praia; inocentemente, os troianos repousam como os carneiros de um

comparação do ardor animal com a impetuosidade da natureza não cessou de fascinar os poetas. Lembremo-nos de um dos "Provérbios do inferno", de William Blake, incluídos no Casamento do Céu e da Terra (The marriage of Heaven and Hell, 1793): "O rugido de leões, o uivo de lobos, a fúria do mar tempestuoso e a espada destruidora são porções de eternidade, grandes demais para o olho do homem".

${ }^{25}$ Cf. Kip, A. M. v. T. The gods of the "Iliad" and the fate of Troy. Mnemosyne. Series IV, vol. LIII, p. 385-402, 2000, em particular p. 393-397: "A ofensa de Páris nunca é matéria de discussão no Olimpo. [...] Ele [scil. o poeta] poderia ter focalizado o sofrimento das vítimas humanas, tanto no símile quanto no contexto da narrativa. Como já o dissemos, ele focaliza o barulho das torrentes e dos cavalos. E uma vez aue os ouvintes sabem que, como um personagem na história, o deus soberano ama os troianos e não quer sua destruição, eles não serão particularmente inclinados a identificar o Zeus da comparação com o Zeus da história".

${ }^{26}$ Cf. Kip, The gods of the "Iliad" and the fate of Troy, p. 395-400. 
homem opulento; uma violência extrema marca o encontro dos dois exércitos (Ilíada IV, 422-451). Para exprimir a extensão da devastação, o poeta recorre a mais uma comparação poderosa:

Havia ao mesmo tempo muitos lamentos e esbravejos dos homens matando e morrendo, a terra escorria de sangue. Assim como rios invernais correm das montanhas e lançam água vigorosa em bacias confluentes, em grandes jorros nos sulcos côncavos, e deles, longínquo, um pastor nas montanhas ouve o retumbar; assim também era a gritaria e a peleja dos combatentes. ${ }^{27}$

Mais à frente, um novo encontro dos dois exércitos é comparado com o assalto dos ventos a uma floresta:

Assim como Euros e Notos disputam-se mutuamente no vale da montanha para atacar o bosque, o carvalho, o freicho e o corniso de longas folhas, que se lançam mutuamente ramos afiados com extraordinário estardalhaço, e seus ramos quebrados estalam; assim troianos e aqueus, lançando-se uns contra os outros, lutavam, jamais pensando na fuga funesta. ${ }^{28}$

Com a agressividade dos ventos o poeta exprime um furor no combate que ultrapassa todas as medidas da experiência humana. Esses dois símiles dos cantos IV e XVI pontuam a longa narrativa da Ilíada com a experiência assustadora da devastação monumental. $^{29}$

Além do combate, os fenômenos naturais também são aproximados da atividade psíquica dos heróis: os tormentos de Agamêmnon durante a noite são comparados com as tempestades enviadas por Zeus (Ilíada X, 1-10); o ardor de Heitor é comparado duas vezes com uma tempestade: quando encoraja seus soldados contra os aqueus e, mais à frente, quando os encurrala no próprio acampamento (Ilíada XI, 292-298 e XII, 35$40) ;{ }^{30}$ em duas passagens a neve é a imagem da abundância das flechas ou das pedras lançadas pelos exércitos (Ilíada XII, 154-161 e 277-289); os numerosos Lícios que, em

${ }^{27}$ Cf. Ilíada IV, 450-456.

${ }^{28}$ Cf. Ilíada XVI, 765-771.

${ }^{29}$ Cf. Austin, N. Archery at the dark of the moon. Poetic problems in Homer's "Odyssey". Los Angeles: University of California Press, 1975, p. 104-105: "Somente quando compreendemos que o mundo exterior é um sistema coerente para Homero, e que o homem é um microcosmo por analogia, podemos começar a falar de psicologia homérica. O pensamento analógico é algo de fundamental para Homero; é através da analogia que os fenômenos e as experiências diversas são atribuídas a uma ou a outra das oposições polares".

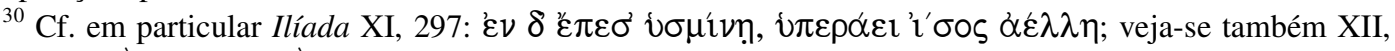

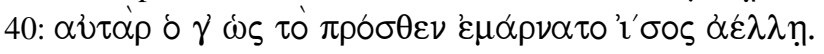


formação compacta, escalam os parapeitos da torre de Menesteu são comparados com o "negro furacão" (Ilíada XII, 370-376); ${ }^{31}$ quando Páris e Heitor se misturam com os troianos "onde é mais forte o combate", o poeta os compara com "a borrasca desencadeada pelos ventos malignos que se abate sobre a terra com o barulho do trovão de Zeus pai" (Ilíada XIII, 795-801); a indecisão de Nestor é aproximada do mar imperturbável antes da tempestade: "Às vezes vê-se o vasto mar estremecer com uma onda muda..." (Ilíada XIV, 16-22). ${ }^{32}$ Uma passagem muito tocante da Odisseia compara o rosto choroso de Penélope com a neve que se funde (Odisseia XIX, 204209).

D. Bouvier mostrou que a Ilíada associa a guerra aos fenômenos naturais para pôr em evidência seu caráter abrupto:

Longe de ser compreendida como um acidente histórico, a guerra é aqui esse flagelo natural ao qual o homem não pode escapar e que os sinais de Zeus anunciam como eles anunciam uma tempestade. Ou o tempo da tormenta ou a realidade da guerra: entre o fenômeno meteorológico e o acontecimento humano, a alternativa sugere uma equivalência inquietante e convida a interrogar sobre o que pode ser uma concepção do tempo que, na lei do céu, reconhece a configuração de um drama humano. ${ }^{33}$

O tempo da guerra não pode ser traduzido por nenhuma outra experiência além das manifestações violentas da natureza, que, por sua vez, não são evocadas fora das comparações: a bruma é manipulada pelos deuses para tornar-se uma cobertura protetora análoga ao escudo de bronze; nas mãos dos deuses, particularmente nas de Zeus, o trovão e a poeira são mais armas do que fenômenos naturais; os combates heroicos acontecem num terreno unido, vazio e desértico, desprovido de qualquer vitalidade. ${ }^{34}$ A guerra é toda pensada como uma tempestade e aparece nas comparações

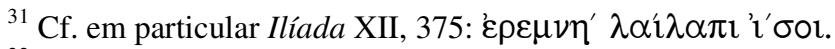

${ }^{32}$ Além de sua gravidade, a imagem deve sua intensidade à comoção que a influente figura de Nestor cria entre os reis aqueus.

${ }^{33}$ Cf. Bouvier, D. La tempête de la guerre. Remarques sur l'heure et le lieu du combat dans l' "Iliade". In: Darbo-Peschanski, C. (org.). Constructions du temps dans le monde grec ancien. Paris: CNRS Éditions, 2000, p. 237-257; p. 237 para a citação.

${ }^{34}$ Cf. Bouvier, op. cit., p. 240-241 e 252: "Zeus não é, no céu da planície de Troia, o deus que vigia a ordem das estações, mas aquele que tira partido de sua maestria dos fenômenos atmosféricos para dirigir os combates dos mortais. (...) Se se excetuam essas brumas e essas nuvens que os deuses utilizam para se dissimular ou abrigar um herói, não há na Ilíada outra meteorologia além da das cores da guerra; outra nuvem verdadeira além daquela com a qual a guerra e a morte cobrem o campo de batalha, outra tempestade possível além da do enfurecimento dos heróis".
} 
que evocam a força devastadora da natureza e do deserto. ${ }^{35}$ A dimensão cósmica da guerra de Troia, que o poema normalmente deixa de lado, reaparece nas comparações. ${ }^{36}$ Além do mais, o vocabulário homérico salienta esse aspecto ao fazer coincidirem os nomes indicativos da força da guerra com os da força da tempestade. ${ }^{37}$

Para uma comparação, observemos como Virgílio acentua ainda mais o aspecto antropomórfico desse tipo de associação, transferindo as características psicológicas dos deuses aos próprios ventos e tempestades (que são deuses nos poemas homéricos, mas sem a autonomia dos deuses principais). ${ }^{38}$ Assim o poeta descreve o "império sobre os ventos rebeldes e as tempestades sonoras" exercido por Éolo:

\section{[...] celsa cedet Aolus arce sceptra tenens mollitque animos et temperat iras; [...].}

Sentado sobre a rocha mais elevada, Éolo, com o cetro na mão, amolece suas almas e tempera suas iras; $[\ldots]^{39}$

Além da associação frequente dos deuses com os cataclismas, a religião grega também parece comparável com outras religiões pelo processo evolutivo por meio do qual o antigo deus supremo celeste é substituído no poder por um outro deus, mais ativo e mais presente na vida dos homens. Essa substituição aproxima os deuses dos homens. M. Eliade considera da seguinte maneira esse processo longo e antigo:

\footnotetext{
35 Veja-se, por exemplo, a batalha pelos despojos de Pátroclo: aqueus e troianos lutam "como o fogo" ( $\delta \dot{\varepsilon} \mu \alpha \varsigma \pi v \rho o ́ \varsigma)$ e ofuscam o presente ao ponto de os impedir de saber-se se o sol e a lua ainda existem (Ilíada XVII, 366-369); contra os aqueus "desdobra-se um combate feroz, semelhante ao incêndio"

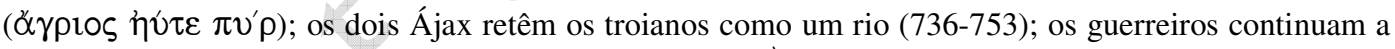

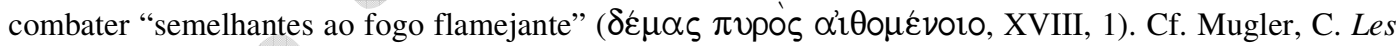
origines de la science grecque chez Homère. L'homme et l'univers physique. Paris: Klincksieck, 1963, p. 3 (a respeito do ardor guerreiro): "Essas forças humanas e seus efeitos são frequentemente comparadas na Ilíada e na Odisseia com as forças da natureza e com seus efeitos. (...) Mas todas essas comparações, muito numerosas, foram precedidas, na representação dos gregos, por comparações em sentido inverso, nas quais as forças da natureza foram assimiladas às forças do homem e dos seres vivos em geral. A epopeia conserva numerosos traços desse antropomorfismo ancestral".

${ }^{36}$ Cf. Bouvier, op. cit., p. 256-257: "Ao longo de todo o poema as comparações fazem ressoar nos limites da planície de Troia o estardalhaço do que teria podido, afinal de contas, ser uma 'guerra cósmica': quando os guerreiros avançam, 'o solo geme pesadamente, como outrora, sob o rancor de Zeus sonante, quando esse errava pela terra em volta de Tifeu' (II, 78ss.). Espaço de lugar algum, poeirento e desértico, a arena do campo de batalha é esse lugar neutro onde, porque ela não ameaça a ordem do mundo divino, a guerra dos homens pode acontecer. Tudo acontece, aqui, como se a guerra fosse temível a tal ponto que obrigasse a lhe achar um espaço próprio".

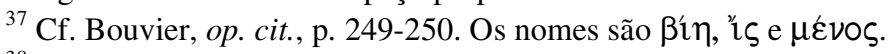

38 Os poemas homéricos não se referem em geral aos ventos como protagonistas de histórias antropomórficas. Para uma exceção, veja-se a menção dos cavalos de Aquiles, Xantos e Balios, que a

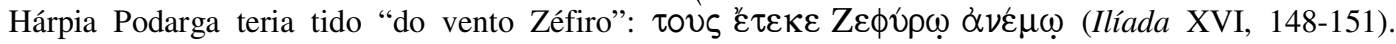
Virgílio fará referência a essa inseminação de Zéfiro em Geórgicas III, 272.

${ }^{39}$ Cf. Eneida I, 56-57.
} 
O que está inteiramente fora de dúvida é a quase universalidade das crenças num Ser divino celeste, criador do Universo e garantidor da fecundidade da terra (graças às chuvas que ele despeja). Tais Seres são dotados de uma presciência e de uma sabedoria infinitas; as leis morais e frequentemente os rituais do clã foram instaurados por eles durante sua breve estadia na terra; eles supervisionam o cumprimento das leis e o raio fulmina quem as infringe. (...) Pelo que se vê, a divindade celeste suprema cede por toda parte o lugar a outras formas religiosas. A morfologia dessa substituição é muito variada; mas o sentido de cada substituição é, em parte, o mesmo: a passagem da transcendência e da passividade dos Seres celestes às formas religiosas dinâmicas, eficientes, facilmente acessíveis. Nós assistimos, poder-se-ia dizer, a uma 'queda progressiva no concreto' do sagrado; a vida do homem e o meio cósmico que o envolve imediatamente se impregnam sempre mais de sacralidade. As crenças nos mana, a orenda, o wakan etc., o animismo, o totemismo, a devoção em relação aos espíritos dos mortos e às divindades locais etc., situam o homem numa posição religiosa diferente da que ele tinha a respeito do Ser supremo celeste. ${ }^{40}$

Contado primeiro na Teogonia de Hesíodo, 126-210 e 453-506, mas já aludido em passagens da Ilíada e da Odisseia, o mito das lutas entre o Céu, Cronos e Zeus inscreve-se nesse vasto processo de retração do deus supremo celeste e da sua substituição por um deus mais próximo dos homens (Teogonia 126-210 e 453-506). ${ }^{41}$ Continuemos a seguir M. Eliade:

${ }^{40}$ Cf. Eliade, op. cit., capítulo II, p. 46-114; p. 46-48 e 57 para as citações. Snell, A descoberta do espírito, p. 77, observa a respeito de Hesíodo: "E o seu Zeus como ordenador do mundo prepara o monoteísmo dos pensadores ulteriores". Burkert, Griechische Religion der archaischen und klassischen Epoche, p. 196, lembra os paralelos hititas das narrativas hesiódicas: "Os dois mitos centrais, o mito da sucessão assim como o da luta, têm em cada um paralelos hititas; eles devem ser considerados empréstimos da Ásia Menor, os quais não chegaram provavelmente pelo intermédio de Hesíodo, mas que só se concretizaram no século VIII a.C.". A nota 31 da p. 196 remete à bibliografia pertinente e observa que o mito da sucessão é suposto na Ilíada pela fórmula "filho de Cronos de pensamento recurvo"

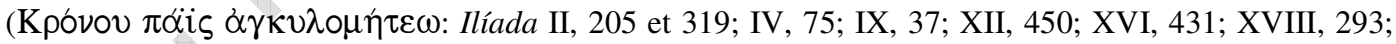
Odisseia XXI, 415), embora essa fórmula deva ser considerada recente do ponto de vista linguístico.

${ }^{41}$ Essa é sem dúvida a cosmogonia mais presente nos poemas homéricos, já que é suposta por quase todos os acontecimentos. Ela é sugerida por Zeus quando o deus, para afirmar sua superioridade em relação a Hera, refere-se aos confins subterrâneos a que foram condenados Jápeto e Cronos (Ilíada VIII, 477-481). Ela também é exposta por Poseidon em seu diálogo com Íris, que viera transmitir-lhe a ameaça de Zeus de puni-lo caso insistisse em intervir na guerra dos mortais (Iíiada XV, 185-193). Finalmente, ela é evocada por duas outras passagens da Ilíada (Ilíada XIII, 354-355 e XV, 165-167). Cf. Janko, R. The Iliad: a commentary IV, ad Ilíada, XIII, 354-355, que observa que nessa passagem e em XV, 165-167, Zeus é o mais velho dos Cronidas, enquanto em Odisseia XIII, 142 e em Hesíodo ele é o mais jovem. Essa segunda versão pode ser uma modificação requerida pela narrativa da tomada de poder. Vejam-se em particular as notas de Richardson, N. J. The homeric hymn to Demeter. Edited with introduction and notes by N. J. Richardson. Oxford: University Press, 1974, ad v. 85 e 86. Uma segunda cosmogonia, aparentemente mais antiga do que a primeira, é sugerida rapidamente em Ilíada XIV, 200-217 e 243-246, quando Hera afirma que os deuses marítimos Oceano e Tétis (Okeanós e Têthys) seriam divindades primordiais. Cf. R Janko, The Iliad: a commentary. Volume IV: books 13-16, ad loc., e Onians, R. B. Les origines de la pensée européenne. Sur le corps, l'esprit, l'âme, le monde, le temps et le destin. Tradução por B. Cassin, A. Debru, M. Narcy. Paris: 1999, capítulos VII e VIII da primeira parte, p. 298-305. 
$\mathrm{Na}$ Grécia, Urano conservou mais nitidamente seus traços naturalistas; ele é o céu. Hesíodo no-lo apresenta (Teogonia, 126 ss.) aproximando-se e estendendo-se em todos os sentidos quando, "todo ávido de amor" e trazendo consigo a noite, ele envolve a terra. Essa hierogamia cósmica revela a vocação celeste. Mas, à parte o mito, nada nos restou de Urano; nem mesmo uma imagem. Seu culto eventual foi usurpado por outros deuses, em primeiro lugar por Zeus. Urano confirma ele também esse destino das divindades celestes supremas de ser gradualmente repelidas para fora da atualidade religiosa, de suportar usurpações sem número, substituições e fusões e acabar sendo esquecidas. (...) Urano era por excelência o Macho fecundador, assim como o eram todos os deuses do céu, assim como o era, por exemplo, Dyaus (chamado suretah, "de bom nascimento", Rig Veda, 4, 17, 4; de seu enlace com sua esposa divina Prthivî nasceram os homens e os deuses; cf. Rig Veda, I, 106, 3; 159, 1; 185, $4,4,56,2$, etc.). ${ }^{42}$

A superioridade da força de Zeus desempenha uma função determinante em toda a narrativa de sua tomada de poder, mas permanece indissociável das artimanhas que caracterizam não apenas suas ações e as de Cronos, como também as de suas respectivas mães, Gaia e Reia. ${ }^{43}$ A astúcia é, dessa forma, uma característica da família divina, e justamente aquela que, desenvolvendo-se com o tempo, permitirá que a nova geração venha à luz, nas duas vezes em que isso se torna um problema. Essas duas ocasiões serão suficientes para deslanchar o processo por meio do qual a procriação se instalará como realidade. A partir de então, a diversificação se beneficiará da proteção de Zeus e tornar-se-á sinônimo de sua soberania. Nessa realidade em que a força se mostra um obstáculo à procriação, a astúcia torna-se muito naturalmente o critério de seleção do novo soberano. Uma vez que Zeus incorporou Métis, ela se integrou ao

\footnotetext{
${ }^{42}$ Cf. Eliade, op. cit., p. 74.

${ }^{43}$ A superioridade da força de Zeus é salientada por Hesíodo no começo da Teogonia: o canto das Musas "glorifica primeiro a raça veneranda dos deuses, começando pelo início (...) depois Zeus, por sua vez, (...) mostrando como, em sua potência, ele é o primeiro, o maior dos deuses

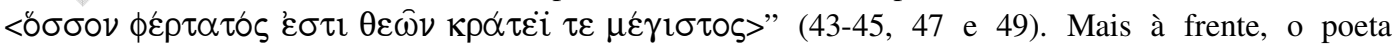
observa que Cronos, tendo engolido uma pedra em lugar de Zeus, não duvidava da existência de seu filho,

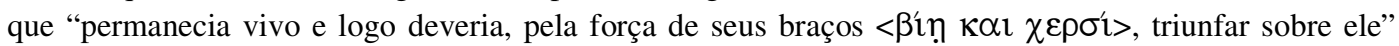
(489-490). Mas depois da vitória de Zeus, o poeta dirá que "Cronos de pensamentos recurvos regurgitou

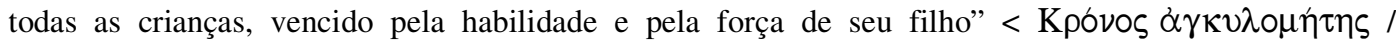

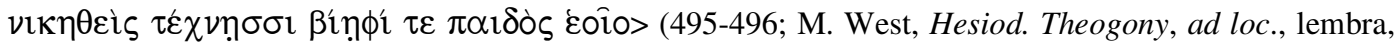
todavia, que em sua edição Heyne considerou suspeita essa linha. Burkert, Mito e mitologia, p. 23-24, salienta a importância do combate de Zeus contra Tífon, incluindo-o no programa mitológico mais amplo da luta dos heróis contra monstros. "O deus mais forte se distingue pelo fato de ter submetido o dragão, ao qual ninguém ousava opor-se. Jahvé de Israel triunfa sobre Leviathan, Marduk da Babilônia, sobre Tiamat, o deus hitita do tempo atmosférico, sobre Illuyankas, Zeus, sobre Tifeu, Apolo de Delfos, sobre Píton”.
} 
exercício do poder olímpico de modo a sempre multiplicar sua capacidade de reação proporcionalmente à renovação da ameaça constituída por novos nascimentos. ${ }^{44}$

Na Teogonia, a astúcia é o princípio capaz de reunir as forças dispersas e virtualmente perigosas da multiplicidade dos deuses e colocá-los ao serviço do poder centralizador de Zeus. É o que mostra exemplarmente o elogio da astúcia de Zeus feito por Cotos, um dos Cem-Braços, quando é convocado com seus dois irmãos por Zeus. Depois de os ter trazido à luz, segundo o conselho de Gaia (Gaíes phradmosyneisin, 626), Zeus lhes havia proposto uma aliança na luta contra os Titãs (644-653). Cotos lhe responde:

\footnotetext{
${ }^{44}$ Cf. Detienne, M.; Vernant, J.-P. Les ruses de l'intelligence. La métis des Grecs. Paris: Flammarion, 1974, p. 19-21, em particular a seguinte passagem: "Por mais forte que seja de fato um homem ou um deus, sempre vem um momento em que ele encontra um mais forte que ele: só a superioridade em métis confere a uma supremacia esse duplo caráter de permanência e de universalidade que faz dela verdadeiramente um poder soberano. Se Zeus é rei dos deuses, se ele supera em potência todas as outras divindades, mesmo mancomunadas contra ele, é porque ele é por excelência o deus de métis. Os mitos gregos que contam a conquista do poder pelo Cronida e a instituição de um reino definitivamente assegurado enfatizam que a vitória no combate para a soberania devia ser obtida, não pela força, mas por uma astúcia, graças à métis. (...) Mas de agora em diante não há mais métis possível fora de Zeus e contra ele. Nenhuma astúcia se trama no universo sem antes passar por seu espírito. A duração através da qual desdobra-se a potência do deus soberano não comporta mais imponderável. Nada que possa surpreendêlo, burlar sua vigilância, contrariar seus desígnios. Alertado pela métis, que lhe é interior, de tudo o que se lhe prepara de bom e de mal, Zeus não conhece mais, entre o projeto e a execução, essa distância por onde surgem, na vida dos outros deuses e das criaturas mortais, as emboscadas do imprevisto".

${ }^{45}$ Teogonia, 655-663. Modifiquei a traducão de J. A. Torrano para essa passagem: Hesíodo. Teogonia. A origem dos deuses. Tradução de J. A. Torrano. São Paulo: Iluminuras, 1992, p. 142-143.
} 
Diferentemente de Uranos e de Cronos, Zeus é um deus associado à existência mortal. É muito significativo que os homens só apareçam na Teogonia depois de sua vitória sobre Cronos e o subsequente acorrentamento deste no Tártaro. Nos Trabalhos e os dias, a cronologia relativa dos acontecimentos humanos e divinos - inclusive seus respectivos nascimentos - é menos clara, já que o poeta não coloca a narrativa da sucessão das idades mortais em relação direta com os acontecimentos divinos. Nesse segundo poema, Hesíodo só menciona a relação entre os mortais e os imortais durante o relato das trapaças de Prometeu, uma narrativa que expõe os impasses do poder de Zeus e, portanto, ainda uma vez, seu recurso hábil à astúcia mais do que à força. ${ }^{46}$

A força é, portanto, valorizada nos episódios da sucessão do poder divino contados por Hesíodo e referidos nos poemas homéricos, mas seu papel é muito relativizado pelo da astúcia. A pluralidade do politeísmo grego não é negligenciada por Hesíodo, mesmo quando se trata de pôr em evidência a incontornável e sublime hegemonia de Zeus. Além do mais, enquanto sucessor de Cronos, Zeus também se mantém distante dos acontecimentos terrestres. Sua força invencível entre os imortais não será mais ativa depois dos dois confrontos contra os filhos de Uranos: primeiro os Titãs (617-735), em seguida Tifeu (820-868). A força de Zeus se torna, nesse sentido, um poder: sua efetividade consiste em sua simples existência. ${ }^{47}$ Nos poemas homéricos - para os quais as lutas pela tomada de poder já fazem parte de uma espécie de "passado" do mundo - as intervenções decisivas de Zeus só se realizam pela interferência de outros deuses, como Atena ou Hermes, ou pelos sinais que envia aos mortais, como o raio. Nos Trabalhos e os dias, é também por sinais que Zeus se faz presente entre nós, ou somente por seus pensamentos. ${ }^{48}$

\footnotetext{
${ }^{46}$ No diálogo platônico Político, a associação de uma idade de felicidade da humanidade ao reino de Cronos é normalmente considerada pelos especialistas uma invenção de Platão.

${ }^{47}$ Além das evidências textuais, Teogonia, 687-718 foram colocados sob suspeita por Mazon, P. Hésiode. Théogonie; Les travaux et les jours; Le bouclier. Edição, tradução e introdução por P. Mazon. Paris: Les Belles Lettres, 1944, talvez por causa de seu caráter excepcional, porque eles contam a luta de Zeus contra os Titãs e constituem um dos momentos do poema em que a força de Zeus é apresentada com a maior ênfase. Entretanto, F. Solmsen, Hesiod. Theogony. Works and days. The shield. Selected fragments. Edição por F. Solmsen, R. Merkelbach e M. West. Oxford: University Press, 1970, e M. West, Hesiod. Theogony. Edição, introdução e notas por M. West. Oxford: University Press, 1982, aceitam a autenticidade da passagem.

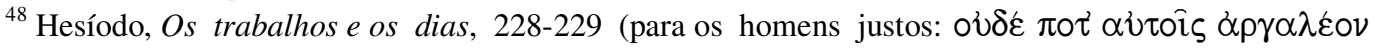

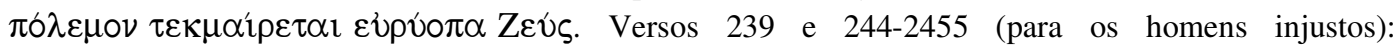

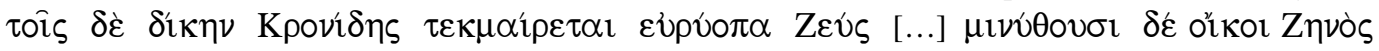

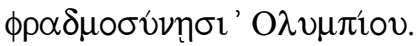


A supremacia do deus soberano desempenha sem dúvida um papel considerável na religião grega. Para M. West, os epítetos de Zeus na Ilíada sugerem que ele seria filho único numa versão mais antiga de seu mito. ${ }^{49}$ A importância da propensão de Zeus a reagir violentamente é, todavia, relativizada pela alternativa da astúcia que o conduziu ao poder e o caracteriza. As narrativas hesiódicas em torno da sua realeza mostram que até Zeus é obrigado a refletir antes de agir.

\section{Referências}

AUSTIN, N. Archery at the dark of the moon. Poetic problems in Homer's 'Odyssey'. Los Angeles: 1975.

BAILLY, A. Dictionnaire Grec-Français. Rédigé avec le concours de E. Egger. Édition revue par L. Séchan et $\mathrm{P}$. Chantraine avec, en appendice, de nouvelles notices de mythologie et religion par L. Séchan. Paris: Hachette, $1963 .^{26}$

BÉRARD, C.; DUNAND, J. L. Entrer en imagerie. In: LISSARRAGUE, F. et alii. La cité des images. Religion et société en Grèce ancienne. Paris: 1984, p. 18-33.

BRELICH, A. Der Polytheismus. Numen. Vol. VIII, 1960, p. 123-136.

BOWRA, C. M. Tradition and design in the "Iliad”. Oxford: Clarendon Press, 1930.

BOTTÉRO, J., KRAMER, S. Lorsque les dieux faisaient l'homme. Mythologie mésopotamienne. Paris: Gallimard, 1989.

BOUVIER, D. La tempête de la guerre. Remarques sur l'heure et le lieu du combat dans 1' "Iliade". In: Darbo-Peschanski, C. (org.). Constructions du temps dans le monde grec ancien. Paris: CNRS Éditions, 2000, p. 237-257.

BURKERT, W. Griechische Religion der archaischen und klassischen Epoche. Die Religionen der Menschheit, 15. Stuttgart: Kohlhammer, 1977.

. Mito e mitologia. Perspectivas do homem. Tradução de M. H. R. Pereira. Lisboa: Edições 70, 1992.

49 Cf. West em M. West, Hesiod. Theogony, p. 36: “os epítetos tradicionais Kpovíwv, Kpovíins, Kpóvov

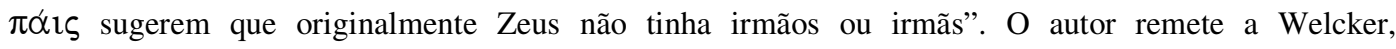
Griechische Götterlehre, I, p. 141 e Wilamowitz-Möllendorf, U. von. Kleine Schriften, v (2), p. 176. 
CLAY, J. S. The wrath of Athena. Gods and men in the "Odyssey". Lanham/ Boulder/ New York/ London: 1997.

CHANTRAINE, P. Le divin et les dieux chez Homère. In: RÉVERDIN, O. (org.). La notion du divin depuis Homère jusqu'à Platon. Entretiens sur l'Antiquité Classique, 1. Vandœuvres (Genebra): Fondation Hardt pour les Études Classiques, 1952, p. 47-94.

A propos d'un nom grec de la force. Emerita. Vol. XIX, p. 134-143, 1951.

DETIENNE, M.; VERNANT, J.-P. Les ruses de l'intelligence. La "métis" des Grecs. Paris: Flammarion, 1974.

. L'invention de la mythologie. Paris: Gallimard, 1981.

DOURADO-LOPES, A. O. O. L'effectivité improbable. Une étude de l'adverbe "rheîa", de l'adjectif "khalepós" et des termes qui en dérivent dans les poèmes homériques. Tese de doutorado defendida junto à Université de Strasbourg sob a orientação de J. Frère. Strasbourg: 2009.

DUMEZIL, G. Homerus vindicatus (le troisième chant de l'"Iliade"). In: L'oubli de l'homme et l'honneur des dieux e autres essais. Vingt-cinq esquisses de mythologie. 5175. Paris: Gallimard, 1985, p. 15-30.

EDWARDS, M. The Iliad: a commentary. Volume V: books 17-20. Editor geral G. Kirk. Cambridge: University Press, 1991.

ELIADE, M. Traité d'histoire des religions. Paris: Payot, $1986{ }^{2}$

ERBSE, H. Untersuchungen zur Funktion der Götter im homerischen Epos. Berlin/ New York: Walter de Gruyter, 1986.

Über Götter und Menschen in der "Ilias" Homers. Hermes. Vol. CXXIV, p. 1-16, 1996.

FRÄNKEL, H. Dichtung und Philosophie des frühen Griechentums. Eine Geschichte der griechischen Epik, Lyrik und Prosa bis zur Mitte des fünften Jahrhunderts. Munique: C. H. Beck, 1993. ${ }^{4}$

FRAZER, J. G. The golden bough. A study in magic and religion. Versão resumida em um volume. New York: Macmillan/ Touchstone, 1922/ 1996.

FRIEDLÄNDER, P. Lachende Götter. Die Antike. Vol. X, p. 209-226, 1934. 
FRONTISI-DUCROUX, F. Les limites de l'anthropomorphisme. Hermès et Dionysos. Le Temps de la Réflexion, 7. Volume temático: "Le corps des dieux", 1986, p. 193-211.

GRIFFIN, J. The epic cycle and the uniqueness of Homer. Journal of Hellenic Studies. Vol. XCVII, p. 39-53, 1977.

GUTHRIE, W. K. The Cambridge Ancient History, vol. II, chapitre XL, fasc. 2,

HELBIG, W. Das homerische Epos. Aus den Denkmälern erläutert. Mit zwei Tafeln und 120 in den Text gedruckten Abbildungen. Leipzig: 1884.

HESÍODO. Hesiod. Theogony. Edição, notas e comentários por M. West. Oxford: Clarendon Press, 1966.

Hésiode; Théogonie; Les travaux et les jours; Le bouclier. Edição, tradução, introdução e notas por P. Mazon. Paris: Les Belles Lettres, 1972.

. Hesiod. Works and days. Edição, notas e comentários por M. West. Oxford: Clarendon Press, 1978.

. Teogonia. A origem dos deuses. Tradução em versos e introdução por J.A.A. Torrano. São Paulo: Iluminuras, 1992.

. Os trabalhos e os dias. Tradução em versos dos 382 versos inicias, introdução e comentários por M. C. N. Lafer. São Paulo: Iluminuras, 1992.

HOMERO. The Iliad. Edição com introdução, notas e apêndices por W. Leaf. Londres, $1900^{2} .2$ vol.

The Iliad. Edição e notas por M. M. Willcock. Londres, 1984. 2 vol.

Homeri "Ilias". Edição por M. West. Stuttgart/ Munique/ Leipzig: Teubner, 1998/ 2000. 2 vol.

HAINSWORTH, B. The Iliad: a commentary. Volume III: books 9-12. Editor geral G. Kirk. Cambridge: University Press, 1993.

HUXLEY, G. L. Greek epic poetry. London: Faber \& Faber, 1969.

JÆGER, W. Die Theologie der frühen Griechischen Denker. Stuttgart: Kohlhammer, 1964. 
JANKO, R. The Iliad: a commentary. Volume IV: books 13-16. Editor geral G. Kirk. Cambridge: University Press, 1992.

KIP, M. v. T. The gods of the "Iliad" and the fate of Troy. Mnemosyne. Series IV, vol. LIII, p. 385-402, 2000.

KIRK, G. S. The songs of Homer. Cambridge: University Press, 1962.

. The Iliad: a commentary. Volume I: books 1-4 (éditeur général G. Kirk), Cambridge: University Press, 1985.

The Iliad: a commentary. Volume II: books 5-8, éditeur général G. Kirk, Cambridge: University Press, 1990.

KULLMANN, W. Das Wirken der Götter. Untersuchungen zur Frage der Entstehung des homerischen "Götterapparatts". Berlin: Akademie, 1956.

LISSARRAGUE, F. Vases grecs. Les Athéniens et leurs images. Paris: Hazan, 1999.

LLOYD, A. B. Herodotus. Book II: commentary 1-98. Leiden: E. J. Brill, 1976.

LLOYD-JONES, H. The justice of Zeus. Sather Classical Lectures. Berkeley/ Los Angeles/ London: University of California Press, $1983 .^{2}$

LORIMER, H. L. Homer and the monuments. Londres: Harcourt, Brace \& World, 1950.

MUGLER, C. Les origines de la science grecque chez Homère. L'homme et l'univers physique. Paris: Klincksieck, 1963.

NAGY, G. G. Resenha de "West (M.), Studies in the text and transmission of the 'Iliad', K. G. Saur, München/ Leipzig, 2001'. Gnomon. Vol. LXXV, n. 7, p. 481-501, 2003.

NILSSON, M. P. Geschichte der griechischen Religion. Munique: C. H. Beck, 1967.3

OLENDER, M. Les langues du paradis. Aryens et Sémites: un couple providentiel. Paris: Gallimard/ Le Seuil, 2002. ${ }^{2}$

ONIANS, R. B. The origins of european thought. About the body, the mind, the soul, the world, time and fate. Cambridge: University Press, $1954 .^{2}$ 
PFISTER, F. "Epiphanie". In: von PAULY, A. F.; WISSOWA, G.; KROLL, W.; WITTE, K.; MITTELHAUS, K.; ZIEGLER, K. Realencyclopädie der klassischen Altertumswissenschaft. Suttgart/ München: 1894-1980. Suplemento 4. 1903, p. 277-323.

PUCCI, P. Theology and poetics in the "Iliad". Arethusa. Vol. XXXV, n. 1, p. 17-34, 2000.

REINHARDT, K. Das Parisurteil. In: Tradition und Geist. Gesammelte Essays zur Dichtung. Editado par C. Becker. Göttingen: Vandenhoek \& Ruprecht, 1960, p. 16-36.

REINHARDT, K. Die Abenteuer der "Odyssee”. In: Tradition und Geist. Gesammelte Essays zur Dichtung. Editado par C. Becker. Göttingen: Vandenhoek \& Ruprecht, 1960, p. 47-124.

. Personnification und Allegorie. In: Vermächtnis der Antike. Essays zur Philosophie und Geschichtschreibung. Göttingen: Vandenhoeck \& Ruprecht, 1989, p. 7-40.

RICHARDSON, N. The "Iliad": a commentary. Vol. VI: books XXI-XXIV. Cambridge: University Press, 1993.

SEGAL, C. Divine justice in the "Odyssey". Poseidon, Cyclopes and Helios. American Journal of Philology. Vol. CXIII, p. 489-518, 1992.

SNELL, B. Der Weg zum Denken und zur Wahrheit. Studien zur frühgriechischen Sprache, (Hypomnemata, 57). Göttingen: Vandenhoeck und Ruprecht, 1978.

. A descoberta do espírito. Trad. de A. Mourão. Lisboa: Edições 70, 1992.

SNODGRASS, A. Homero e os artistas. Texto e pintura na arte grega antiga. Tradução de L. A. M. Cabral e O. T. Serra. São Paulo: Odysseus, 2004.

TRÜMPY, H. Kriegerische Fachausdrücke im griechischen Epos. Untersuchungen zum Wortschatze Homers. Basel: Paulusdrückerei, 1950.

VERNANT, J,-P. Les origines de la pensée grecque. Paris: Quadrige/ Presses Universitaires de France, 1990.

WEST, M. The rise of the Greek Epic. Journal of Hellenic Studies. Vol. CVIII, p. 151172, 1988. 